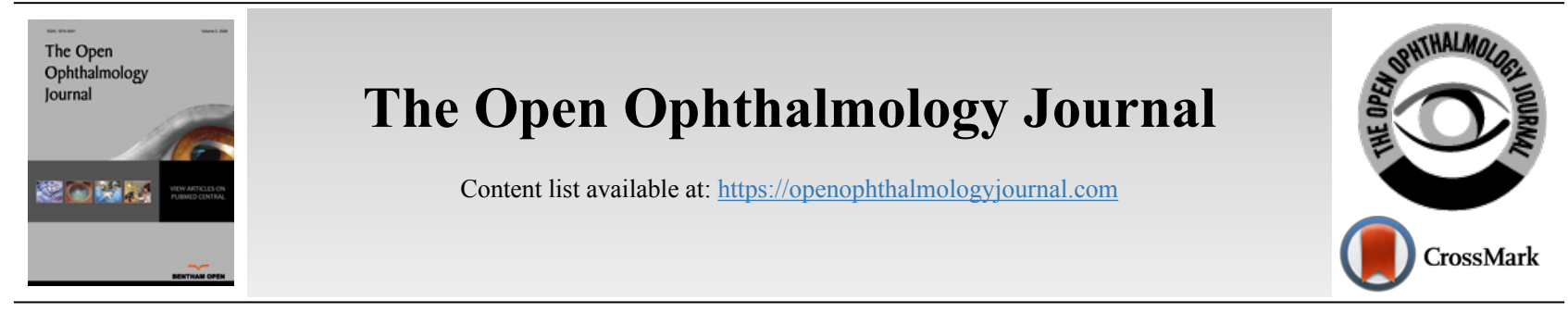

RESEARCH ARTICLE

\title{
Repeatability and Reproducibility of Tear Film Evaporation Rate Measurement using a new Closed-Chamber Evaporimeter
}

\author{
Ali A. Abusharha ${ }^{1, *}$, Ali Al Yami ${ }^{1}$, Khaled Alsreea ${ }^{1}$, Raied Fagehi ${ }^{1}$, Ali Alsaqr ${ }^{1}$, Saud Alanazi ${ }^{1}$ and Ali Masmali ${ }^{1}$

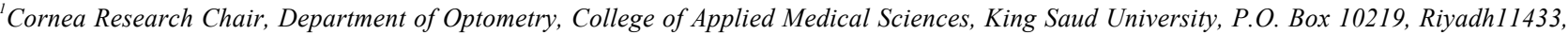 \\ Saudi Arabia
}

\begin{abstract}
:
Purpose:

This study evaluates the repeatability and reproducibility of tear film evaporation rate measurement using a commercially available handheld closed-chamber evaporimeter (VapoMeter, Delfin Technologies, Finland).

Study Design:

This was a randomized observational study, in which two visits were required. At visit 1, screening tests were performed on the participants. Subsequently, tear evaporation was measured thrice by examiner 1 (E1). The procedure was then repeated by examiner 2 (E2) at visit 2.

\section{Methods:}

40 healthy participants with no ocular diseases were recruited for this study. A closed chamber evaporimeter was used in this study (VapoMeter, Delfin Technologies, Finland). Primary investigations, including slit-lamp examination, tear production test, and ocular discomfort, were performed during the first visit for the purpose of screening.

\section{Results:}

The mean of the three measurements of tear evaporation obtained by examiner 1 at visit 1 was $19.38 \pm 0.79 \mathrm{~g} / \mathrm{m}^{2} / \mathrm{h}$, and the mean of the three readings obtained by examiner 2 at visit 2 was $20.49 \pm 0.48 \mathrm{~g} / \mathrm{m}^{2} / \mathrm{h}$. The average Intraclass Correlation Coefficient (ICC) among the three readings of tear evaporation was 0.84 and 0.63 with a $95 \%$ confidence interval (CI) at visits 1 and 2, respectively. A comparison of the reliability of the measurements from the two examiners revealed an ICC of 0.69 with a $95 \% \mathrm{CI}$.

\section{Conclusion:}

The VapoMeter provides repeatable and reproducible measurements of tear film evaporation. This study demonstrates that the VapoMeter could provide clinicians with a readily available method for rapid evaluation of tear film evaporation. By considering the significance of tear evaporation as a diagnostic tool for dry eyes, the VapoMeter may help to diagnose better and manage dry eye syndrome.
\end{abstract}

Keywords: Tear film, dry eye, tear evaporation rate, dry eye syndrome, diagnostic tool, Vapo Meter.

\begin{tabular}{ll|l|l} 
Article History & Received: December 23, 2020 & Revised: March 1, 2021 & Accepted: March 21, 2021
\end{tabular}

\section{INTRODUCTION}

Evaporative dry eye is one of the main classification groups of symptomatic dry eye syndrome [1]. Evaporative dry eye can be caused by many factors, including meibomian lipid deficiency, low blink rate, lid aperture, or dynamics disorders. Furthermore, extrinsic factors, including wearing contact lenses

\footnotetext{
* Address correspondence to this author at Cornea Research Chair, Department of Optometry, College of Applied Medical Sciences, King Saud University, P.O. Box 10219, Riyadh 11433, Saudi Arabia; E-mail: aabusharha@ksu.edu.sa
}

or exposure to adverse environmental factors, could cause evaporative dry eye $[1,2]$.

The lipid layer plays an important role in tear film stability. The nonpolar phase of the lipid layer is responsible for controlling the water vapor evaporation from the aqueous layer [3]. However, chronic ocular diseases, such as blepharitis, may lead to meibomian gland dysfunction and affect lipid secretion, thereby altering the lipid layer of the tear film $[4,5]$. Several diagnostic tools have been proposed to clinically diagnose and monitor dry eye syndrome. One of these diagnostic methods is 
evaluating the evaporation rate of the tear film. In this technique, the average water loss from the exposed ocular surface is measured while the eye is open [6].

Different clinical techniques have been used to assess tear film evaporation since the first studies by Hamano et al. and Rolando et al. in the 1980s [7, 8]. In the 1990s, a new method using the principle of measuring vapor pressure produced by relative humidity between two points was used by Yamada and Tsubota [9]. In this method, a moisture sensor was inserted into a chamber covering the eye $[9,10]$. Later, Tress and Tomlinson have developed a new humidity evaluation unit using the same principle [11]. Here, a Servomed evaporimeter was modified by attaching swimming goggles and linking them to a computer for the analysis and storage of data [11, 12].

However, the benefits of these methods were overweighed by many drawbacks, including complicated setup and modification processes, requiring many instruments to be connected together to measure, analyze, and store data. Because of these design issues, these instruments are not portable and commercially available. Furthermore, they need longer testing times to measure tear evaporation than new techniques that take a few seconds to provide the final evaporation values. These drawbacks are the leading cause for the inability of these techniques to be used clinically and the unavailability of a commercial device for clinically evaluating the tear film evaporation rate. For overcoming these disadvantages, a novel noncontact technique using infrared thermographic imaging of the ocular surface has been proposed $[13,14]$. However, further studies on this methodological approach are needed to validate and assess its accuracy.

Transepidermal water loss is an essential parameter used to assess skin barrier function [15]. The VapoMeter (Delfin Technologies, Kuopio, Finland), a closed-chamber evaporimeter, is a commonly used device for evaluating this transepidermal water loss in dermatology clinics $[16,17]$. In this study, we used a modified, commercially available dermatology device to measure the tear film evaporation rate. This study evaluated the repeatability and reproducibility of tear film evaporation rate measurement using the VapoMeter, a commercially available closed-chamber evaporimeter.

\section{METHODS}

\subsection{Participants}

40 healthy participants without ocular diseases were recruited for this study (mean age, $22.39 \pm 2.33$ years). Ethical approval was obtained from the College of Applied Medical Science Research Center, King Saud University. The study was conducted according to the ethical principles enshrined in the Declaration of Helsinki. Informed consent was obtained from all participants after explaining the study procedure.

\subsection{Screening Investigations}

Primary investigations, including slit-lamp examination, tear production test, and ocular discomfort, were performed during the first visit for screening. Tear production was evaluated using the phenol red thread test (PRT), and the Ocular Surface Disease Index (OSDI) questionnaire was used to assess ocular discomfort. Participants with any ocular disease and those who were contact lens wearers were excluded from this study.

\subsection{Tear Evaporation Test}

The VapoMeter, a closed-chamber evaporimeter, was used in this study. This is a handheld portable device used for measuring transepidermal water loss. The device was modified by attaching swimming goggles to measure the evaporation rate of the eye and surrounding skin [18]. The device consists of two sensors that monitor changes in relative humidity and temperature inside the chamber. The evaporation rate $\left(\mathrm{g} / \mathrm{m}^{2} / \mathrm{h}\right)$ is automatically calculated and displayed on the device screen.

\subsection{Clinical Procedures}

The study protocol required examinations at two visits. All tear evaporation evaluations were performed after 11 am to avoid possible variations in measurements in which the relative humidity and ambient temperature of the examination room were monitored. At visit 1 , screening tests were performed on all participants. Then, three tear evaporation measurements were obtained by examiner $1(\mathrm{E} 1)$. The same procedure was performed by examiner 2 (E2) at visit 2 .

Noninvasive measurements of the evaporation rate were obtained by placing the VapoMeter over the participants' eyes. The measurements were obtained with the eyes open and closed to account for evaporation from the surrounding skin. During open-eye measurements, the participants were instructed to look straight and not blink during the test.

\subsection{Statistical Analysis}

The data were analyzed using Statistical Package for the Social Sciences, version 22 (IBM Corp., Armonk, NY, USA). The normality of data distribution was tested using the Kolmogorov-Smirnov test. Repeated-measures analysis of variance was performed for normally distributed data whereas non-normally distributed data were analyzed using the Friedman test and post-hoc Wilcoxon rank-sum test. The intraclass correlation coefficient (ICC) was calculated to assess the inter-rater and intra-rater reliability of the data collected at each visit. The correlation between parameters was assessed by calculating Pearson correlation and Spearman rank-order correlation coefficients for the normally and non-normally distributed data, respectively.

\section{RESULTS}

40 participants were enrolled in this study (40 men: mean age, $22.39 \pm 2.33$ years). The mean tear production value obtained using the PRT was $23.59 \pm 5.90 \mathrm{~mm}$, and the average OSDI score was $7.11 \pm 6.20$.

The three tear evaporation rate measurements obtained by E1 at visit 1 are shown in Fig. (1A). The mean of these three readings was $19.38 \pm 0.79 \mathrm{~g} / \mathrm{m}^{2} / \mathrm{h}$ while the mean of the three tear evaporation readings obtained by E2 at visit 2 was $20.49 \pm$ $0.48 \mathrm{~g} / \mathrm{m}^{2} / \mathrm{h}$ (Fig. 1B). The mean values for the three evaporation rate readings obtained at each visit are shown in Table 1. 
Using the VapoMeter, no significant difference was noted between the three readings measured at visit $1(p=0.68$, Friedman test). Similarly, no significant difference was observed between the three readings obtained at visit $2(p=$ 0.73 , Friedman test).

The average ICC over the three readings of evaporation rate was 0.84 and 0.63 with a $95 \%$ confidence interval (CI) at visits 1 and 2, respectively. A comparison of the reliability of the measurements from the two examiners (reproducibility) showed an ICC of 0.69 with a $95 \%$ CI. No statistically significant correlation was found between the tear parameters assessed in this study (Fig. 2).

\section{DISCUSSION}

This study assessed the repeatability and reproducibility of the tear film evaporation rate measurement using a commercially available device. The development and availability of a new technology, the VapoMeter (Delfin Technologies, Finland) can help clinicians evaluate tear film evaporation easily and rapidly. Tear evaporation rate readings are produced within seconds, without contact, or disturbance of, tear film layers.

Since 1980, many studies have been conducted using various methods to measure the tear evaporation rate [19]. Methods including measuring fluid loss from the ocular surface and interferometric measurements of tear film thinning have

(A)

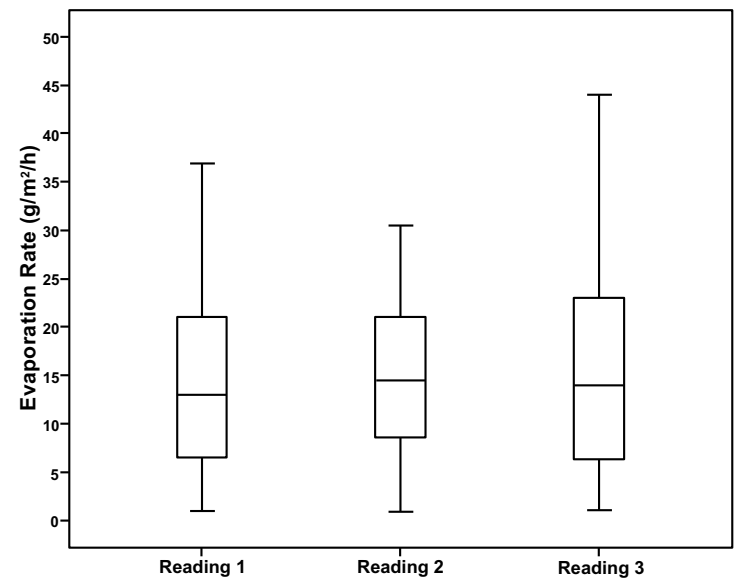

been widely used to estimate the tear evaporation rate [20,21]. Due to the use of different techniques, the evaporation rate is reported in different units, including $\mu \mathrm{L} / \mathrm{min}, \mathrm{g} / \mathrm{m}^{2} / \mathrm{h}$, and $10^{-7}$ $\mathrm{g} / \mathrm{cm}^{2} / \mathrm{s}$ [19].

Numerous attempts have been made to measure the tear evaporation rate in healthy individuals and those with dry eyes. Studies have shown that the evaporation rate in healthy individuals ranged between 0.04 and $0.07 \mu \mathrm{L} / \mathrm{min}$ (14.4 and $25.2 \mathrm{~g} / \mathrm{m}^{2} / \mathrm{h}$ ) [20, 22, 23]. However, studies conducted in the 1990s have estimated a higher evaporation rate among healthy individuals compared to more recent studies. These studies have indicated that values between 0.11 and $0.16 \mu \mathrm{L} / \mathrm{min}(39.6$ and $57.6 \mathrm{~g} / \mathrm{m}^{2} / \mathrm{h}$ ) are considered the normal range of the evaporation rate $[10,24]$.

However, the conflict between studies regarding the tear evaporation rate could be due to the fact that tear evaporation measurement is strongly influenced by the surrounding environment. Many studies have shown that the evaporation rate of the tear film was affected by the changes in relative humidity $[12,25]$. Furthermore, other factors, such as ambient temperature and airflow, affect the measurement of the tear evaporation rate [26]. Therefore, the conflicting results between studies could result from the differences in environmental factors, such as humidity, temperature, and airflow. In this study, humidity and temperature were monitored during evaporation rate measurements to minimize variations induced by the ambient environment.

(B)

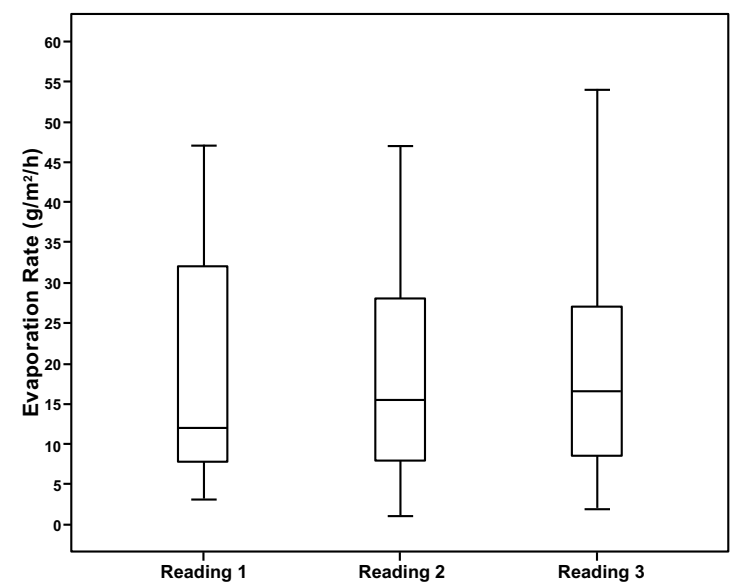

Fig. (1). A box plot showing tear evaporation rate measurements taken at visits 1 (A) and 2 (B); The whiskers are lines extending from the box to the highest and lowest values. The line across the box indicates the median value.

Table 1. Means and standard deviation for the three evaporation rate measurements $\left(\left(\mathrm{g} / \mathrm{m}^{2} / \mathrm{h}\right)\right.$ obtained at visit 1 and visit 2 .

\begin{tabular}{|c|c|c|}
\hline & Visit 1 & Visit 2 \\
\hline Reading 1 & $18.49 \pm 18.26$ & $20.49 \pm 17.75$ \\
\hline Reading 2 & $19.46 \pm 18.9$ & $20.95 \pm 19.84$ \\
\hline Reading 3 & $20.00 \pm 20.77$ & $19.79 \pm 14.71$ \\
\hline
\end{tabular}




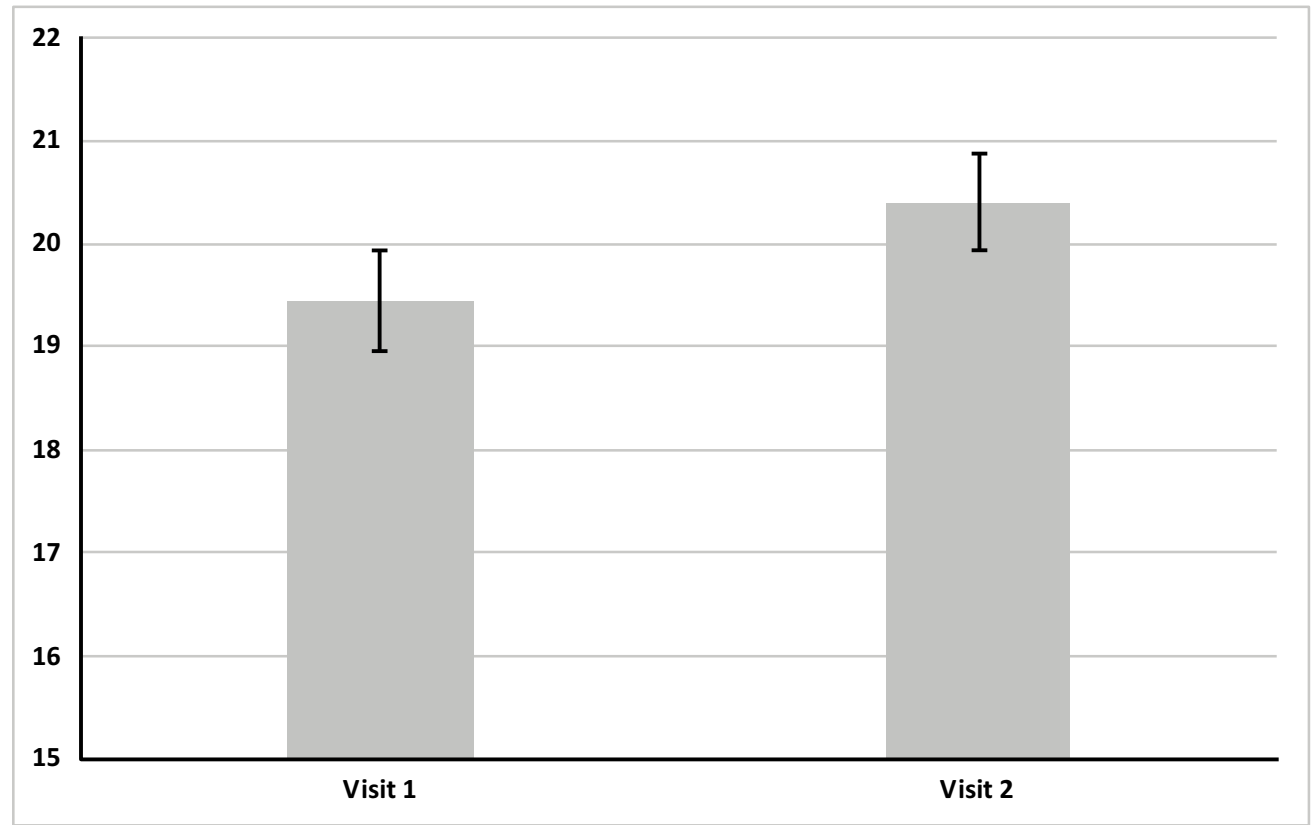

Fig. (2). A box plot showing the mean of the three tear evaporation readings obtained at visits $1(19.38 \pm 0.79 \mathrm{~g} / \mathrm{m} 2 / \mathrm{h}) \mathrm{and} 2(20.49 \pm 0.48 \mathrm{~g} / \mathrm{m} 2 / \mathrm{h})$; The whiskers are lines extending from the box to the highest and lowest values. The line across the box indicates the median value.

Measurement of the evaporation rate is an essential tool in the differential diagnosis of dry eye syndrome [19]. Several studies have shown that tear evaporation is greater in patients with aqueous deficiency and meibomian gland dysfunction. Furthermore, studies have suggested that water loss from the ocular surface ranges between 0.1 and $0.24 \mu \mathrm{L} / \mathrm{min}$ (36 and 86 $\mathrm{g} / \mathrm{m}^{2} / \mathrm{h}$ ) in patients with dry eyes $[27,28]$.

This study found that the mean tear evaporation rate in healthy participants measured using the VapoMeter was 19.38 and $20.49 \mathrm{~g} / \mathrm{m}^{2} / \mathrm{h}(0.05$ and $0.06 \mu \mathrm{L} / \mathrm{min})$ at visits 1 and 2 , respectively. These results conform to the findings of other studies that have found that the tear evaporation rate in healthy participants was between 0.04 and $0.07 \mu \mathrm{L} / \min$ [19, 23, 29]. This also conforms to earlier observations, which have shown that the mean tear evaporation rate in healthy participants was $20.97 \mathrm{~g} / \mathrm{m}^{2} / \mathrm{h} \mathrm{[22]}$.

This study showed that performing a tear evaporation test using the modified evaporimeter in healthy participants produced consistent tear evaporation measurements without significant differences between the measurements obtained in different sessions by the same examiner and those obtained by other examiners $(p>0.05)$. The ICC reliability test indicated a moderate to good repeatability $(I C C=0.89$ with a $95 \% C I)$ and reproducibility $(I C C=0.69$ with a $95 \% C I)$ of tear film evaporation rate measurements using the VapoMeter.

\section{CONCLUSION}

The results of this study suggest that the VapoMeter provides repeatable and reproducible measurements of the tear film evaporation rate. This study showed that the VapoMeter could provide clinicians with a readily available method for rapid evaluation of the tear film evaporation rate. Measuring tear evaporation rate using VapoMeter eliminates many of the previously reported disadvantages of old techniques, such as prolonged testing time and the complicated setup and modification processes needed. The handheld VapoMeter can be used to measure the tear film evaporation rate for the possible diagnosis of evaporative dry eye. By considering the significance of tear evaporation as a diagnostic tool for dry eye syndrome, this instrument may help clinicians to diagnose better and manage dry eye syndrome.

\section{ETHICS APPROVAL AND CONSENT TO PARTICIPATE}

This study was approved by the College of Applied Medical Science Research Center, King Saud University, Saudi Arabia under ethical approval no. CAMS 002a-3839.

\section{HUMAN AND ANIMAL RIGHTS}

No Animals were used in this research. All human research procedures followed were in accordance with the ethical standards of the committee responsible for human experimentation (institutional and national), and with the Helsinki Declaration of 1975, as revised in 2013.

\section{CONSENT FOR PUBLICATION}

Informed consent was obtained from all participants after explaining the study procedure.

\section{AVAILABILITY OF DATA AND MATERIALS}

Not applicable.

\section{FUNDING}

The authors extend their appreciation to the Cornea Research Chair, Optometry Department, College of Applied Medical Sciences, King Saud University for its funding for this research. 


\section{CONFLICT OF INTEREST}

The authors declare no conflict of interest, financial or otherwise.

\section{ACKNOWLEDGEMENTS}

The authors extend their appreciation to the Cornea Research Chair, Optometry Department, College of Applied Medical Sciences, King Saud University for its funding for this research.

\section{REFERENCES}

[1] Lemp MA, Baudouin C, Baum J, et al. The definition and classification of dry eye disease: Report of the Definition and Classification Subcommittee of the International Dry Eye WorkShop Ocul Surf 2007; 5: 75-92.

[2] Lemp MA. Advances in understanding and managing dry eye disease. Am J Ophthalmol 2008; 146(3): 350-6.

[http://dx.doi.org/10.1016/j.ajo.2008.05.016] [PMID: 18599017]

[3] McCulley JP, Shine WE. The lipid layer: The outer surface of the ocular surface tear film. Biosci Rep 2001; 21(4): 407-18.

[http://dx.doi.org/10.1023/A:1017987608937] [PMID: 11900319]

[4] McCulley JP, Shine WE. The lipid layer of tears: Dependent on meibomian gland function. Exp Eye Res 2004; 78(3): 361-5. [http://dx.doi.org/10.1016/S0014-4835(03)00203-3] [PMID: 15106913]

[5] Foulks GN. Blepharitis lid margin disease and the ocular surface. Ocul Surf Dis Med Sur Man 2002; pp. 39-48.

[http://dx.doi.org/10.1007/0-387-21570-0_3]

[6] Foulks GN, Bron AJ. Meibomian gland dysfunction: A clinical scheme for description, diagnosis, classification, and grading. Ocul Surf 2003; 1(3): 107-26.

[http://dx.doi.org/10.1016/S1542-0124(12)70139-8] [PMID: 17075643]

[7] Hamano H, Hori M, Hamano T, et al. A new method for measuring tears. The CLAO journal: Official publication of the Contact Lens Association of Ophthalmologists. Inc 1983; 9: 281-9.

[8] Rolando M, Refojo MF. Tear evaporimeter for measuring water evaporation rate from the tear film under controlled conditions in humans. Exp Eye Res 1983; 36(1): 25-33.

[http://dx.doi.org/10.1016/0014-4835(83)90086-6] [PMID: 6825731]

[9] Yamada M, Tsubota K. Measurement of tear evaporation from ocular surface. Nippon Ganka Gakkai Zasshi 1990; 94(11): 1061-70. [PMID: 2075869]

[10] Tsubota K, Yamada M. Tear evaporation from the ocular surface. Invest Ophthalmol Vis Sci 1992; 33(10): 2942-50. [PMID: 1526744]

[11] Trees GR, Tomlinson A. Effect of artificial tear solutions and saline on tear film evaporation. Optom Vis Sci 1990; 67(12): 886-90.

[http://dx.doi.org/10.1097/00006324-199012000-00002] [PMID: 2082235]

[12] Madden LC, Tomlinson A, Simmons PA. Effect of humidity variations in a controlled environment chamber on tear evaporation after dry eye therapy. Eye Contact Lens 2013; 39(2): 169-74.

[http://dx.doi.org/10.1097/ICL.0b013e318283dfc6] [PMID: 23411993]

[13] Petznick A, Tan JH, Boo SK, Lee SY, Acharya UR, Tong L. Repeatability of a new method for measuring tear evaporation rates. Optom Vis Sci 2013; 90(4): 366-71.

[http://dx.doi.org/10.1097/OPX.0b013e318288bdd1] [PMID: 23435224]

[14] Tan JH, Ng EY, Acharya UR. Evaluation of tear evaporation from ocular surface by functional infrared thermography. Med Phys 2010; 37(11): 6022-34

[http://dx.doi.org/10.1118/1.3495540] [PMID: 21158314]

[15] Kottner J, Lichterfeld A, Blume-Peytavi U. Transepidermal water loss in young and aged healthy humans: A systematic review and metaanalysis. Arch Dermatol Res 2013; 305(4): 315-23.

[http://dx.doi.org/10.1007/s00403-012-1313-6] [PMID: 23341028]

[16] De Paepe K, Houben E, Adam R, Wiesemann F, Rogiers V. Validation of the VapoMeter, a closed unventilated chamber system to assess transepidermal water loss $v s$. the open chamber Tewameter. Skin Res Technol 2005; 11(1): 61-9.

[http://dx.doi.org/10.1111/j.1600-0846.2005.00101.x] [PMID: 15691261]

[17] Imhof RE, De Jesus ME, Xiao P, Ciortea LI, Berg EP. Closedchamber transepidermal water loss measurement: Microclimate, calibration and performance. Int J Cosmet Sci 2009; 31(2): 97-118. [http://dx.doi.org/10.1111/j.1468-2494.2008.00476.x] [PMID: 19175433]

[18] Rohit A, Ehrmann K, Naduvilath T, Willcox M, Stapleton F. Validating a new device for measuring tear evaporation rates. Ophthalmic Physiol Opt 2014; 34(1): 53-62.

[http://dx.doi.org/10.1111/opo.12096] [PMID: 24205915]

[19] Tomlinson A, Doane MG, McFadyen A. Inputs and outputs of the lacrimal system: review of production and evaporative loss. Ocul Surf 2009; 7(4): 186-98.

[http://dx.doi.org/10.1016/S1542-0124(12)70186-6]

[PMID 19948102]

[20] Goto E, Endo K, Suzuki A, Fujikura Y, Matsumoto Y, Tsubota K. Tear evaporation dynamics in normal subjects and subjects with obstructive meibomian gland dysfunction. Invest Ophthalmol Vis Sci 2003; 44(2): 533-9.

[http://dx.doi.org/10.1167/iovs.02-0170] [PMID: 12556380]

[21] King-Smith PE, Nichols JJ, Nichols KK, Fink BA, Braun RJ. Contributions of evaporation and other mechanisms to tear film thinning and break-up. Optom Vis Sci 2008; 85(8): 623-30.

[http://dx.doi.org/10.1097/OPX.0b013e318181ae60]

[PMID: 18677230]

[22] Khanal S, Tomlinson A, Diaper CJM. Tear physiology of aqueous deficiency and evaporative dry eye. Optom Vis Sci 2009; 86(11): 1235-40.

[http://dx.doi.org/10.1097/OPX.0b013e3181bc63cc]

[PMID: 19770810]

[23] Tomlinson A, Pearce EI, Simmons PA, Blades K. Effect of oral contraceptives on tear physiology. Ophthalmic Physiol Opt 2001; 21(1): 9-16.

[http://dx.doi.org/10.1016/S0275-5408(00)00005-3] [PMID: 11220045]

[24] Mathers WD, Binarao G, Petroll M. Ocular water evaporation and the dry eye. A new measuring device. Cornea 1993; 12(4): 335-40. [http://dx.doi.org/10.1097/00003226-199307000-00010] [PMID: 8339563]

[25] Abusharha AA, Pearce EI. The effect of low humidity on the human tear film. Cornea 2013; 32(4): 429-34.

[http://dx.doi.org/10.1097/ICO.0b013e31826671ab]

[PMID: 23023409]

[26] Borchman D, Foulks GN, Yappert MC, Mathews J, Leake K, Bell J. Factors affecting evaporation rates of tear film components measured in vitro. Eye Contact Lens 2009; 35(1): 32-7.

[http://dx.doi.org/10.1097/ICL.0b013e318193f4fc] [PMID: 19125046]

[27] Khanal S, Tomlinson A, Esakowitz L, et al. Changes in corneal sensitivity and tear physiology after phacoemulsification. Ophthalmic Physiol Opt 2008; 28(2): 127-34.

[http://dx.doi.org/10.1111/j.1475-1313.2008.00539.x] [PMID: 18339043]

[28] McCann LC, Tomlinson A, Pearce EI, Papa V. Effectiveness of artificial tears in the management of evaporative dry eye. Cornea 2012; 31(1): 1-5.

[http://dx.doi.org/10.1097/ICO.0b013e31821b71e6]

[PMID: 21968605

[29] McCulley JP, Shine WE, Aronowicz J, Oral D, Vargas J. Presumed hyposecretory/hyperevaporative KCS: Tear characteristics. Trans Am Ophthalmol Soc 2003; 101: 141-52. [PMID: 14971572] 